\title{
THE INFLUENCE OF HOSPITAL ISOLATION ON SCARLET FEVER IN HEREFORD.*
}

\author{
By J. B. FITZSIMONS, M.D., \\ Late Medical Officer, Hereford Isolation Hospital.
}

As you are aware, there has been carried on during the past few years a somewhat desultory controversy upon the influence of hospital isolation on scarlet fever, and when I was asked to read a paper at this meeting, it appeared to me that inasmuch as most statistics have been, up to this time, taken from the records of large towns, containing congested areas, it might be of interest, in the first place to see how hospital isolation has worked out in a small, openly built town like Hereford, the centre of an agricultural district ; and secondly, to enquire if any subject for consideration, bearing reference to the Hereford Isolation Hospital, arises from the discussion, in so far as it has already proceeded.

As many of the papers on the subject of hospital isolation have been, in recent years, read before this Society, and published in the Society's journal, you are doubtless well acquainted with them, and probably have noted that in some cases the same statistics, looked at from different points of view, appear to lead to diametrically opposite conclusions, and one is led to speculate as to the value of the conclusions derivable solely from such statistics.

I can give you an instance of the possibility of drawing different conclusions from the same figures, examined per se, taken from the scarlet fever records of the city of Hereford : of course pigmy statistics in comparison with those drawn from the large towns, but interesting in themselves, as showing what different conclusions might be derived from such records, looked at from varying standpoints, and also interesting as to their bearing upon the question of hospital isolation in a small town. The figures themselves $I$ extract from the scarlet fever statistics of Hereford, compiled by Dr. Cecil Moore, the Medical Officer of Health for the city, and published in his very valuable report for 1903 .

Looking therefore at Dr. Moore's scarlet fever statistics, we note first that the Hereford Isolation Hospital, an iron hospital lined with wood and having felt between, was opened on May 18th, 1893. Taking then the total results of the ten pre-hospital years, and comparing them with the results of the ten succeeding hospital years, we obtain.

${ }^{-}$Read before the West of England and South Wales Branch of the Incorporated Society of Medical Officers of Health. 
the following tables, premising that during the first seven of the ten pre-hospital years, notification, although existing, was voluntary, and therefore it is probable that the attack rate was higher than the figures denote:-

\begin{tabular}{|c|c|c|c|c|c|}
\hline & 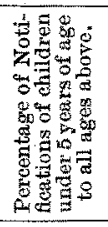 & 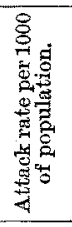 & 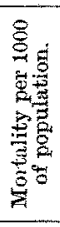 & 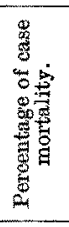 & 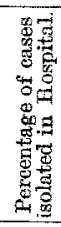 \\
\hline $\begin{array}{l}\text { Average of tem pre-hospital } \\
\text { years } \\
\text { Average of ten hospital years }\end{array}$ & $\begin{array}{l}38 \cdot 1 \\
41 \cdot 9\end{array}$ & $\begin{array}{l}1 \cdot 44 \\
3 \cdot 81\end{array}$ & $\begin{array}{l}\cdot 06 \\
\cdot 13\end{array}$ & $\begin{array}{l}4 \cdot 1 \\
3 * 4\end{array}$ & $\begin{array}{c}0 \\
50.3\end{array}$ \\
\hline
\end{tabular}

These figures, looked at in this way, would appear to indicate that the attack rate, column 2, and mortality per 1000 of population, column 3 , and the percentage of notifications of children under five years of age to all ages above, column 1 , had been considerably increased, and the percentage of case mortality, column 4, very little reduced, by the establishment of an isolation hospital in Hereford, and the isolation of half the cases occurring, column 5. But if we divide the second ten-year period into two periods of five years each, we get the very different results shown in the following table, to which $I$ have added two more columns ;-column 1, giving the percentage of children under five years of age to the total population, taken in 1891 and 1901 ; and column 5, showing the mortality per 1000 of children under five years of age, taken by themselves.

\begin{tabular}{|c|c|c|c|c|c|c|c|}
\hline 1 & & 2 & 3 & 4 & 5 & 6 & 7 \\
\hline 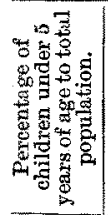 & & 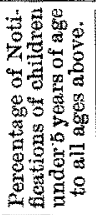 & 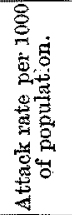 & 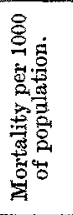 & 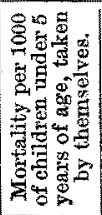 & 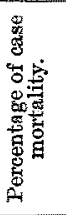 & 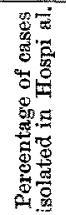 \\
\hline $\begin{array}{c}\operatorname{In} 1891 \\
11 \cdot 0\end{array}$ & $\begin{array}{cc}\text { Average of first five } \\
\text { hospital years }\end{array}$ & $45 \cdot 58$ & 5881 & 24 & $1 \cdot 7$ & $4 \cdot 1$ & $32-8$ \\
\hline $\begin{array}{c}\operatorname{In} 1901 \\
10^{\circ}\end{array}$ & $\begin{array}{l}\text { Average of second five } \\
\text { hospital years }\end{array}$ & $30 \cdot 4$ & 1.81 & 016 & 0.0 & 1.01 & 67.8 \\
\hline
\end{tabular}

From this table you will see that in the first five hospital years, column 7, 32:8 per cent of the cases occurring in Hereford were isolated. In the second five hospital years, no less than $67^{\circ} 8$ per cent were isolated; and then, looking at the various columns, we see that in the first of these hospital periods, column 3 , the attack rate was 5.81 per 1000 of 
the population; in the second, it had fallen to 1.81 . The mortality per 1000 of the population, column 4 , which was 24 in the first period, fell to 016 in the second ; the percentage of case mortality, column 6 , fell from 4.1 to 1.01 ; the mortality per 1000 of children under five years of age, taken by themselves, column 5 , fell from $1 \cdot 7$ to 0 ; and the percentage of notifications of children under five years of age to all ages above, column 2 , fell from $45 \cdot 58$ to 304 .

Such happy results, occurring when the percentage of cases isolated was more than doubled, would appear to be confirmatory of the value of hospital isolation, as carried out in the smaller towns; the only adverse point being that the attack rate per 1000 of the population, column 3, which in the second hospital period of five years had fallen to 1.81 , was not even then as low as during the pre-hospital period, Table I, column 2, when it stood at 1.44 ; but as I said before, during seven of the ten pre-hospital years notifications were not compulsory, and had they been so, the attack rate would probably have been much higher.

But in considering the value of hospital isolation, if we desire to arrive at reliable conclusions, my own opinion is that much more should be taken into consideration than mere figures. For instance, as regards the Hereford statistics, it should be borne in mind that during the three years following the opening of the isolation hospital, there was an epidemic wave of scarlet fever, there having been, as shown by Dr. Moore's table, no less than 466 notifications in the first three years after the opening of the hospital, since which period there has been a gradual decline in the incidence of the disease, until last year, 1903 , there were only 24 cases notified.

We must also remember that the majority of cases of scarlet fever treated at home, are those in less crowded or larger houses, where there is a spare room, or rooms, and where home isolation is possible, whilst cases removed to hospital are mostly taken from small homes, often crowded with inmates, where there is no spare room, and no possibility of isolation. In such cases the hospital may fairly be termed the poor man's spare room, and when we meet with such cases, occurring in crowded homes, with no possibility of isolation, we cannot help wondering what the result might have been, had such hospital accommodation not been available.

One can quite understand that if the hospital accommodation be too small for the number of cases admitted during, perhaps, a period of epidemic, and that overcrowding of cases ensues, the results as regards fatality might compare unfavourably with results of cases treated in homes of a somewhat better class, where, as I have said, isolation can be fairly carried out. And it seems hardly fair to quote 
the results of hospital isolation in towns where the hospital is always crowded, and where eases have to be kept at home until there is a vacant bed, and to omit statistics taken from small towns like Hereford, which have, in proportion to the population, much more sufficient hospital accommodation, where there is in consequence no overcrowding, and where the hospital wards, from time to time, as opportunity occurs, can be closed and thoroughly cleansed and disinfected. Under such conditions the results would naturally be more favourable. And I think you will probably agree that statistics must be obtained, extending over a much larger area, including country towns as well as the more densely populated cities, and, together with such records, you must be fully in possession of the surrounding circumstances, and varying conditions, of the different centres, before you can arrive at any decision adverse to the present system of hospital isolation.

I have referred to the statistics of Hereford as pigmy statistics, but in the year 1876 they certainly could not have been so termed. Unfortunately, of that year, no statistics are available except the number of deaths, and we can only guess at the probable number of cases from the number of deaths. In that year in Hereford there were 75 deaths, giving a mortality of 3.90 per 1000 of the population, and I can easily imagine that the attack rate must have been correspondingly high.

Then secondly, I proposed to enquire if any subject of interest, bearing reference to the Hereford Isolation Hospital, arises from the consideration of the various papers which have been written on the subject of hospital isolation. One point occurs to me, as to the length of time convalescents should be retained in hospital prior to discharge.

Dr. Foord Caiger, in Clifford Allbutt's System of Medicine, says : "The period of quarantine should not be less than six weeks." But from an editorial published in the Journal of State Medicine, in March, 1903, I gather that the period of detention in the hospitals of the Metropolitan Asylums Board is nine weeks, and that it varies in different hospitals throughout the country, from that lengthened period down to about four or five weeks at Leicester. In Hereford our custom in the majority of cases, where nothing occurs to contraindicate it, has been to discharge the patient after six weeks detention, and this, I think, is the safest period, as judged by results, that is, as judged by the number of return cases.

In 1899 the Metropolitan Asylums Board, in whose hospitals, as I have said, the patients appear to be detained nine weeks, requested Dr. W. J. Simpson to make an investigation into all return cases of 
scarlet fever connected with their infectious hospitals, from October 1898 to March 1899; the return cases, before investigation, giving a percentage of 3.8 . And on inquiry, after deducting all doubtful cases, and all cases in which "no evidence was furnished of their being return cases," and also, "all cases in which it was impossible to dissociate infected clothing, or house infection, from personal infection," he found there still remained, as admittedly true return cases, a percentage of $1 \cdot 3$. Amongst the other conclusions Dr. Simpson arrived at from his investigations, as given in his report, was the following: "That mere duration of detention in hospital is no standard as to the limit of infection, and no guarantee that the patient shall be freed of infection; and that long detention in infectious wards will not reduce the percentage of return cases." And further on he adds, "that a reduction in the duration of the detention of scarlet fever and diphtheria eases in hospital, would likely tend to a greater control over the prevalence of scarlet fever and diphtheria in the metropolis, as it would permit of a larger number being removed to hospital with the same accommodation as at present." Dr. Simpson's report was subsequently referred to the Royal College of Physicians, who decided that there was not sufficient evidence at present before them, to enable them to lay down any definite period of time, as necessary for the detention of patients recovering from scarlet fever. In Hereford, where as I have said we discharge the majority of patients in six weeks, the return cases, since the establishment of the hospital, give a percentage of only $\cdot 62$. This favourable result leads us to speculate, not only whether it might not be wiser to reduce the period of detention, especially in the crowded hospitals of the larger towns, thereby rendering the wards less crowded, and by so much more healthy for the remaining inmates, but also as to whether the argument that patients would do better at home, based on statisties drawn from towns where the hospitals are overcrowded, should not rather be considered as an argument for the expenditure of a further amount of public money, so as to render the accommodation of such hospitals equal to the needs of the surrounding communities.

Prizes for Cleanliness.-The Public Health Committee of Belfast has adopted a somewhat novel scheme of offering prizes to occupiers of small houses the rent of which does not exceed 4 s. weekly. The prizes consist of allowances to cover the rent for specified periods (the first prize being one year's rent), and these will be awarded to the competitors who keep their houses, yards, and premises, including furniture, utensils, and windows, cleanest and in the most sanitary condition between certain given dates. The author of the scheme is Mr. Robert Meyer, Chief Clerk of the Corporation. 